\title{
Ecological Strategy of Water Landscape Planning: Harbin as a Case Study
}

\author{
Sun Hongtao ${ }^{1, a}$, Hou $\mathrm{Yu}^{2, \mathrm{~b}}$, Huang Muzi $\mathrm{i}^{3, \mathrm{c}}$ \\ ${ }^{1,2,3}$ School of Architecture and Urban Planning, Shenyang Jianzhu University, Shenyang, China \\ a Sunhongtao328@126.com, ${ }^{\mathrm{b}}$ Houyu @163.com, ${ }^{\mathrm{c}}$ Huangmuzi @126.com
}

Keywords: Frigid city.Waterfront city.Water landscape planning.Ecological strategy

\begin{abstract}
As an important city of Songhua River Basin, the ecological pattern of urban landscape in Harbin not only has the common characteristics with frigid cities, but also has its own distinctive characteristics. The thesis made research of structural layout of water space and development direction of landscape planning, and proposed ecological strategy of water landscape planning from three levels: water-city structure of Harbin, waterfront ecology and river green wedge.
\end{abstract}

\section{Introduction}

Songhua River, one of the seven major rivers in China, is an important water system, located in the northeast of the country. Among plenty of integrated waterfront cities in the basin of the Songhua River, Harbin is located in the middle reaches, with common characteristics of cold waterfront city in its urban landscape ecological pattern. Meanwhile, Harbin also has its own distinctive characteristics ${ }^{[1]}$.

As one of many cities on the Songnen Plain, Harbin city mainly terraces formed in the Songhua River. From southwest to northeast Songhua River, total length of $71.3 \mathrm{~km}$, flows through Harbin. There are a lot of water branches and aits in Harbin, such as Daowai Midlle Island, Jiangbei Sun Island, Binbeiqiao Middle Island and so on. In addition, there are also many shoals and side beach along the rivers. Three tributaries - Majia River, Hejia River and Ashi River-sinks in Songhua River finally(Fig.1). Large green patches mainly in the urban fringe, distributed along the Songhua River tributaries. Sun Island, a dune island in the Songhua River in Harbin, is the most important ecological patch of urban ecological landscape pattern ${ }^{[2]}$.

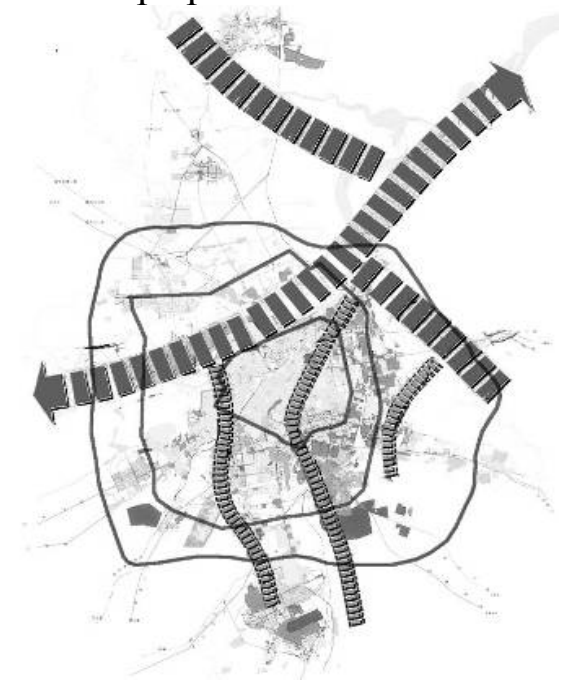

Fig.1 Ecological Landscape Characteristics of Harbin

From the whole basin's point of view, since the city of Harbin is located in the heart of the plain in the middle reaches of the Songhua River, its carrying capacity of the natural environment is stronger, but the sensitivity of the ecosystem is higher than the upstream cities. What's more, the ecological damage caused by environmental consequences of improper urban construction will 
expand exponentially in the downstream. The complexity and diversity of the natural ecological environment of Harbin, make a variety of landscape ecology elements function differ, and cause the ecological differences and diversify of landscape style of the local environment.

\section{Integration of Urban Form and the Natural Environment}

In 2012, the actual resident population of Harbin City is 350.1 million, increasing by 27.7 million compared with that in 2002. With the increasing total population, the growing tense situation of urban land and the expansion of urban space, determination on the direction of urban development and selection of construction land is being influenced more and more greatly by Harbin's and the surroundings' natural landscape and ecological structure. Harbin's natural environment is an ecosystem that is based on the vast farmlands, natural patches (southern and eastern forests, Hulan River, Ash River Delta, south of the Songhua River and North Wetland) and ditch corridor (the Songhua River, Ash River, Hulan River, Majia River, Hejia River and Xinyi River). (Fig.2)

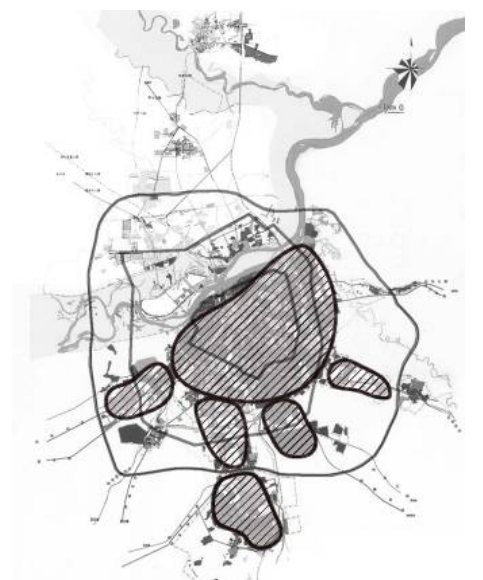

Fig. 2 Analysis of the Matrix around Harbin Metropolis ${ }^{[2]}$

Based on the analysis of waterfront city in morphological characteristics, for the relationship of urban growth and the surrounding natural spaces, the star radial city perform as the one with a compact central district. This kind of urban pattern avoid the waste of land resources and urban encroachment on the natural surroundings caused by the spread of the city. Along the public traffic routes, city extends from the center to the surrounding area, like fingers, that meet the needs of expansion without any influence on the function of the city. For example, Copenhagen, the capital of Danish, uses a palm- star-shaped urban form which is supported by a well-functioning public transport system, recognized as a sustainable city ${ }^{[3]}$.Besides, the spaces between the digital-shaped extended axes of star radial city provide room for the green wedge extending, increase the length of the contact surface between the urban patch and matrix, and facilitate the exchange of internal and external environment. (Fig.3)
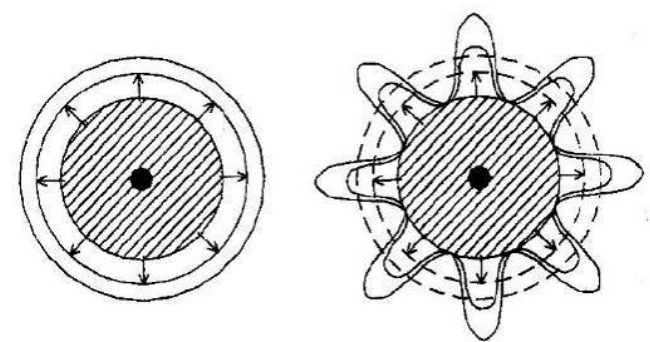

Fig.3 Circular Shape Patch and Digital Shape Patch

In Harbin, the present River Wetland Corridor System that is mainly based on the Songhua River has clear direction and restriction function on the future layout of urban space. The wide 
green corridor formed by Ashi River and the trunk stream of Songhua River has played a defining role in the continuous development of the city to the north and to the east, so that across development of the city can only appear in independent group mode. On the other side, three tributaries of the Songhua River Corridor-Majia River, Hejia River and Xinyi River-across through the city, combine with the natural environment surrounding the city, play the role of connecting the urban ecological environment to the external ecological matrix, and introduce country landscape into city zone. Green wedge, formed on the base of three tributaries mentioned before, stretch into the city of Harbin. The area between the water system and green wedge is the finger-like extensions of the city space. The radial public transport corridors constitute the city's stretching axes. Through the annular rapid transit, axes are connected. (Fig.4)

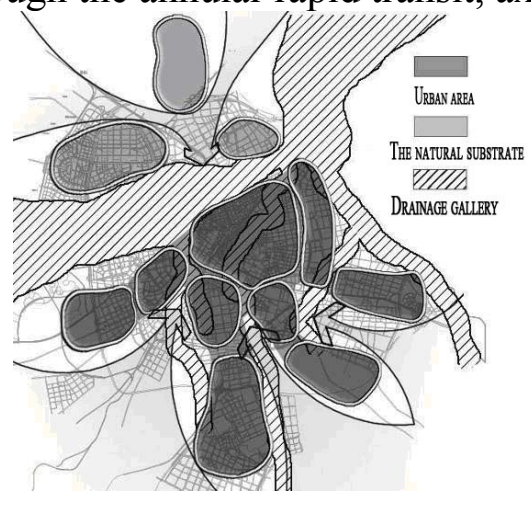

a) Urban Space Development Form

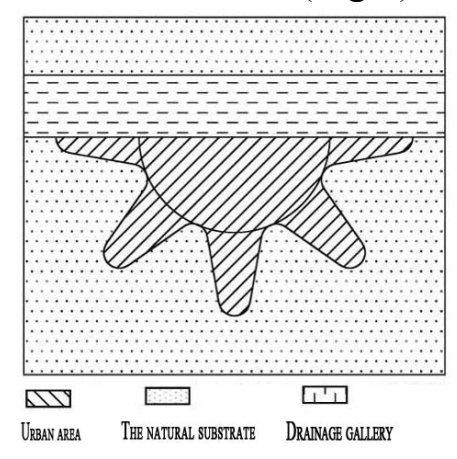

b) Space Expansion Mode

Fig.4 Analysis of Urban Spatial Structure of Harbin Metropolis

On the basis of the existing river ecological corridor system in Harbin, ecological framework has been built, which is named One River, Two Rivers, Three channels and Four Lakes. As the urban river system corridor has the most intensive natural factor and the most abundant natural processes in the city, it is the natural eco-axis of the city. Through the comprehensive analysis of the evolution law of urban space, the regional natural landscape structure, the regional transportation network and the economic direction, the construction condition and the development threshold, we see that the main development direction of the city of Harbin is radial outstretched transformational pattern from single center to multi center circle. By combining with urban transportation corridors radiating outward, planning the future development of urban space and defining the green wedge basic protection areas and buffer zones clearly, we can prevent the erosion of the urban construction of green institutionally. On the other side, along the traffic line, the form of finger-like urban sprawl also reduces the pressure on green space; the green wedge in the structure will not be divided and fragmented. Thereby, we can avoid the deterioration of the urban environment and the damage to aquatic ecosystems, which is caused by contiguous urban space that is too large. (Fig.4)

\section{Protection of Ecological Diversity Patterns}

In the development of Harbin, protecting the natural conditions and ecological environment of wetlands along the river and rational use of wetland landscape resources has become long-term task of ecological construction in Harbin. For transformation of river systems, must be careful enough. Not only to study the landscape pattern, but also should we evaluate the task in terms of the ecological functions and so on, to protect diversified water landscape pattern along the river.

1, Protection of the Existing Ecological Structure

The coastal flood area of Songhua River includes a large area of floodplain, wet meadows, islands, and shoals, and ecological system of river valley floodplain with island forest and island vegetation features and natural landscape elements. Endless flood waters may extend dozen kilometers. The wildlife resources are also abundant ${ }^{[4]}$. We must fully realize the importance of the landscape features and environmental function of the north bank floodplain wetland to the 
landscape construction of Harbin, instead of simply regarding it as the urban peripheral land to exploit and utilize. In the floodplain wetland on the north bank of Songhua River, natural landforms should be the absolute subject. Intercity highway and urban loop through the wetland, flood control dam and the scenic spots and other man-made activities area should not exceed $20 \%$ of the total area. The stability of the ecological system of the north bank floodplain and the integrity of the natural landscape unit are protected by this way.

2, Flood Protection Space

Floodplain wetlands along the Songhua River are wetland vegetation-covered area, located in the periphery of the city and integrated with the urban area. During the flood period of wet year, wetlands can take $20 \sim 25 \%$ water of the Songhua River. The water surface area accounts for more than $60 \%$ of the total area. It is necessary to protect adequate flood discharge area and its natural distribution state, Maintain its natural vegetation, protect the tributary of Songhua River flowing throughout the north coast of the whole wetland-the coast of Jinshui River and other flood overflow channels, restore the distribution of natural water system of flood wetland on north bank, keep the river network usually, ensure the function of flood release and the complement of wetland, water ponds, and recognize the inevitability of flood and The significance of maintaining the wetland landscape. We should not dam excessively and artificially, contrary to the laws of nature, destroy the precious natural heritage and urban long-term ecological interests in order to pursue the economic interests of the immediate land value.

\section{3, Eco Park Construction}

As important city natural landscape element and residual patch of Harbin, northern bank floodplain wetland ecosystem and Songhua River itself, inlaid in the edge of the city, not only maintain its independent natural attributes, but also integrate with urban development organically. This perfect ecological landscape layout strongly influences the overall urban landscape design and effectiveness in horizontal distribution and space, enhances the overall aesthetic feeling of the city, increases the naturalness of the city, and fully reflects the coordination of the city's natural elements and artificial elements. Thence, artificial attractions and the necessary facilities should to be coordinated with the natural landscape feature keynote. Typical locations should be selected to establish different types of wetland ecosystem science education demonstration parks, such as island forests, marsh willow thickets, meadows, wet meadows, meadow marshes, bogs, floodplains and so on, in other to increase their knowledge and raise their awareness of ecological protection when people are fully enjoying outdoor leisure and natural beauty.

\section{Construction of River Ecological Green Wedge}

Medium and small green patches occupied area of $43.66 \%$ in Harbin. They are numerous (Table.1), widely distributed, and closely related to the daily life of the public. However, due to the small area, landscape fragmentation and other issues, its ecological effectiveness is low. On the contrary, these small and medium sized patches and the large green outskirts can be connected in series by rivers throughout the city, such as Majia River, Hejia River, and Xinyi River, to enhance the eco-efficiency of urban green space landscape pattern. (Fig.5) 


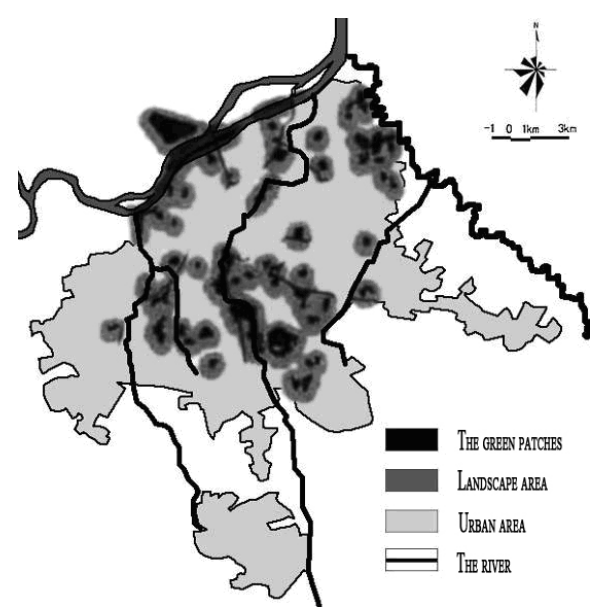

Fig.5 River Corridors and Green Patches in Harbin

Table 1 Types of Urban Greenbelt Catches in Harbin

\begin{tabular}{l|c|c|c|c}
\hline Patch Type & Area $(\mathrm{hm} 2)$ & Proportion (\%) & Number & Proportion (\%) \\
\hline Small Patches & 391.50 & 21.55 & 7814 & 86.19 \\
\hline Medium Patches & 401.66 & 22.11 & 1020 & 11.25 \\
\hline Medium-to-Large Patches & 423.11 & 23.29 & 196 & 2.16 \\
\hline Large Patches & 600.55 & 33.06 & 36 & 0.40 \\
\hline Total & 1816.82 & 100 & 9066 & 100 \\
\hline
\end{tabular}

Harbin Planning Bureau has proposed to construct the green channel named Three Ditches and One River and achieve group layout. However, when planning the green corridor, people should pay special attentions to a variety of functions. In addition to the cultural and leisure corridor, it should be designed as continuous channels of natural processes, to establish a contact corridor among the country landscape the north and the south of the city, enhance the vitality of the surrounding environment and activate city space and create dynamic landscape.

\section{Conclusion}

1, Restoration of Water Environment and Protection of Diverse Waterfront Ecological Pattern

The restoration of urban rivers emphasizes the recovery of the system function due to the disturbance of the city river, to achieve the self-improvement of ecosystem ultimately ${ }^{[5]}$. In the large-scale urban construction process of the city along Songhua River, the neglect of the protection of the ecological environment lead to serious pollution and the damage to aquatic ecosystems. Therefore, the first thing to establish the ecological pattern is the restoration of the ecological environment. We should Restore natural river, ensure river natural space, protect diverse waterfront ecological patterns and protect the stability of flooding wetland ecosystem and the integrity of natural landscape units. The floodplain wetlands of Songhua River drainage and urban areas are important landscape elements for the cities in the river basin of the Songhua River. They integrate with the organic development of the city, maintaining relative natural attributes. This kind of eco landscape layout influences the effect of the whole urban landscape design strongly in space, enhances the city's natural and overall refinement of city, and reflects the coordination of natural elements and artificial elements in the city. Artificial construction of facilities in these areas must follow this feature, coordinated with the natural landscape tone.

2, Attention to the Transformation of the Waterfront area and Playing a Role in Aquatic Ecosystems

Most of cold waterfront urban spaces expand along the water. Natural water plays an important role in the city space frame, with status of a link between the urban spaces. Waterfront zone is the main space for the innovation and function layout of the city in the future. We should optimize the ecological axes' position of river system in urban ecological pattern. The important principle of the construction of ecological pattern is to strengthen the connection of various natural environment 
elements, construct the overall ecological network structure, and improve the ecological carrying capacity and Anti-interference ability.

3, Increasing Green Patches, Integration of Urban Structure and Water and Green Network

From the target of urban residents, measures would been taken: increasing the number and size of green patches and establishing diverse types of green landscape systems, to balance service radius classification and exert its influence on the residents' physiology, psychology and aesthetic ability. It's also important to increase the number of public green space in urban center, expand large parks around the city, and protect country natural forest and agricultural production green space. The important principle of the landscape ecological planning strategy is to strengthen the connection of various natural environment elements, construct the overall ecological network

structure, and improve the ecological carrying capacity and Anti-interference ability ${ }^{[6]}$. For the water is the soul of the city, we ought to strengthen the link between urban green patch and water system corridor, what is the key to guarantee the transfer and flow of natural elements and protect the ecological features of the city. Therefore, combining with water, road, corridor and other linear elements of ecological green corridor, urban internal and external ecological patches should be connected, to form the ecological corridor of air, water, insects and birds. Three networks - "Green Network", "Water Network" and "Traffic Network" — that go through whole of the city's green system, interweave each other and constitute a whole, organic and perfect urban green space system.

\section{References}

[1] the Piece of Songliao Water Conservancy Committee. the Volume of the Songhua River. China Water\&Power Press, 1994:1 9

[2] Harbin Planning Bureau. Master Plan of Harbin (2004-2020). Internal Data, 2003

[3] Timothy Beatley. Green Urbanism: Learning from European Cities. Washington D C Island, 2000:491

[4]Wang Tianming, Wang Xiaochun, ect. Continuity and Integrity of Urban Greenbelt Landscape Pattern and Process .Chin J Appl Environ Biol, 2004,10(4):402 407

[5] M Hough. City Form and Nature Process. Routledge,1989:280

[6] [America] Ian Lennox McHarg. Design With Nature. Translated by Ri Jingwei. China Translation \& Publishing Corporation (CTPC), 1992:183 219, 56,152,135 